\title{
BALLENEROS EN LA NIEBLA: UNA MIRADA PARA-ETNOGRÁFICA DE LA CAZA DE BALLENAS EN CHILE
}

\author{
WHALERS IN THE FOG: \\ PARA-ETHNOGRAPHIC OUTLOOK OF WHALING IN CHILE
}

\author{
Daniel Quiroz ${ }^{1}$
}

\begin{abstract}
La captura de ballenas en las costas de Chile es un "evento del pasado". Su estudio requiere el uso de herramientas metodológicas no tradicionales de la etnografía. El término "etnografía retrospectiva" sirve para nombrar un enfoque que busca "miradas y "voces equivalentes" a las que tendríamos si tuviéramos la posibilidad de observar la caza de ballenas y escuchar a sus practicantes en un "presente etnográfico". En esta oportunidad nos interesa mostrar las "miradas y voces" de Luis Castillo, biólogo, y Francisco Coloane, escritor-periodista, quienes observaron y describieron las actividades balleneras en un momento específico de su historia ¿Son sus observaciones equivalentes las que podría haber hecho un etnógrafo en esa misma época? Pensamos que Castillo y Coloane representan lo que hemos denominado "etnógrafos equivalentes" o "para-etnógrafos", es decir, sujetos expertos que no son nativos ni colegas, sino contrapartes del etnógrafo.
\end{abstract}

Palabras claves: caza de ballenas, etnografía retrospectiva, para-etnografía, etnógrafos equivalentes.

Whaling off the coast of Chile is a "past event". Its study requires the use of non-traditional ethnographic methodological tools. The phrase "retrospective ethnography" is used to refer to an approach that looks for "views" and "voices" equivalent to those we would have were it possible to observe whaling and listen to whalers at the "ethnographic present". In this paper, we show the "views and voices" of Luis Castillo, biologist, and Francisco Coloane, writer-reporter, who observed and described the whaling activities at a specific moment in history. Are their observations similar to those an ethnographer could have made at the same time? We believe that Castillo and Coloane represent what we have called "equivalent ethnographers" or "para-ethnographers", expert subjects who are neither native nor colleagues of the ethnographer but their counterparts.

Key words: Whaling, retrospective ethnography, para-ethnography, equivalent ethnographers.

La niebla es un fenómeno meteorológico en el que nubes de baja altura reducen la visibilidad "a menos de mil metros". Pero es también un "fenómeno poético" que permite hablar de aquello cuyas formas precisas no conocemos, de cosas escondidas que, por encontrarse a "más de mil metros", no podemos ver con claridad. El historiador francés Marc Bloch nos recuerda que nos movemos "medio ciegos y medio sordos por un mundo exterior que solo vemos y comprendemos por medio de una especie de niebla" (Bloch 2008:24). Pensar en la niebla nos obliga a considerar que muchas veces lo buscado se desvanece para volver a aparecer con formas nuevas, desafiando las teorías y metodologías más conocidas y populares. El escritor uruguayo Mario Benedetti nos pide considerar en nuestras cavilaciones "cómo cambian las cosas/en la niebla" y nos advierte que "la niebla no es olvido/sino postergación anticipada" (Benedetti 1974:7).

Nos interesa "reconstruir" la caza de ballenas en/ desde las costas de Chile en forma "retrospectiva", sin desconocer que solo tenemos fragmentos dispersos y que siempre estamos "en medio de la niebla".

\section{La Caza de Ballenas}

La caza de ballenas con propósitos comerciales se inicia en el mundo occidental a partir del siglo $\mathrm{X} \mathrm{u} \mathrm{XI}$ de nuestra era, cuando pescadores vascos capturan ballenas francas en el golfo de Vizcaya para obtener grasa, aceite, carne y barbas que vendían por toda Europa. Estas operaciones se caracterizaban por el uso de botes abiertos, propulsados a remo o vela, desplegados desde la costa o desde barcos

1 Centro de Documentación de Bienes Patrimoniales, Dirección de Bibliotecas, Archivos y Museos, Recoleta 683. Santiago 8420260, Chile. Daniel.Quiroz@museosdibam.cl 
fondeados cerca de ella. La caza de ballenas se efectuaba con arpones y lanzas de mano, cuyas carcasas eran remolcadas a tierra para procesarlas (Azpiazu 2000).

La caza pelágica de origen estadounidense, que comienza a fines del siglo XVIII, domina la escena durante casi todo el siglo XIX. Se usaban veleros de unas 300 a 400 toneladas, tripulados por 30 a 40 hombres. Los veleros llevaban varios botes que eran bajados y usados en la caza cuando se divisaban las ballenas. Los botes eran tripulados por seis personas: un timonel en la popa, cuatro remeros y un arponero en la proa. Uno o más arpones eran lanzados contra la ballena desde muy corta distancia. Normalmente la ballena no moría sino que huía, remolcando a los botes. Cuando se cansaba era muerta por el timonel que manejaba una lanza que la hundía en uno de los órganos vitales. La ballena era llevada a un costado del velero, donde era descuartizada. La grasa era retirada y subida a bordo mediante poleas. La principal innovación era la transferencia del proceso de transformación de la grasa de la ballena en aceite desde instalaciones costeras a la cubierta de un buque, donde había grandes hornos de ladrillo (Davis et al. 1997).

La presencia de estos buques en las costas chilenas estimulará diversos emprendimientos nacionales, llegando a conformar en 1868 una flota de 19 barcos balleneros bajo bandera chilena en la pesca de la ballena (Figura 1). Cada año iban al archipiélago de las Galápagos y al golfo de Panamá a la caza de ballenas (Cartes 2009; Pereira Salas 1971).

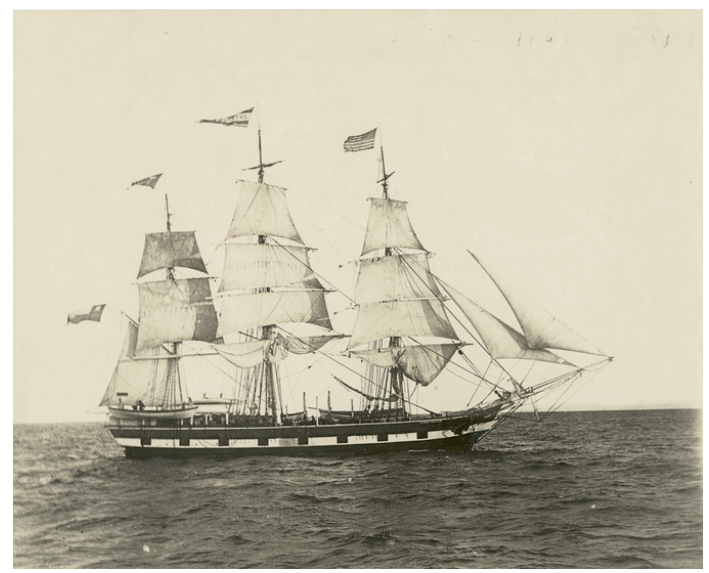

Figura 1. Navío James Arnold bajo bandera chilena, 1894 [Tarjeta postal de propiedad del autor].

James Arnold ship under Chilean flag, 1894 [Postcard owned by the author].
Junto a las actividades "empresariales" se desarrollarán en el país varias operaciones balleneras costeras, denominadas tradicionales, con chalupas y arpones de mano (Quiroz 2012), siendo las más conocidas las de José Olivares, en Tumbes, Talcahuano (Fernández 1966), y de Juan Macaya, en la isla Santa María (Hernández 1998). Las primeras referencias acerca de pescadores tradicionales de ballenas son de 1853 (Quiroz 2012:2). Operaban en las costas de Concepción, extendiendo luego su área de captura a la isla Santa María, desembocadura del río Lebu, Valdivia, Maullín y Chiloé (Quiroz 2012:2-4).

La caza moderna de ballenas, que se inicia en la segunda mitad del siglo XIX en el norte de Noruega, se caracterizaba por usar un buque ballenero de vapor con "un arpón explosivo lanzado desde un cañón montado en la proa" (Brown 1976:25). El buque ideal debía ser "rápido, poderoso, maniobrable y virtualmente imposible de hundirse" (Davis et al. 1997:500). Las carcasas eran procesadas en instalaciones costeras para producir aceite y abono o en buque-factorías que funcionaban como plantas flotantes, ancladas cerca de la costa (Tønnessen y Johnsen 1982).

Este tipo de caza se inicia en Chile en la primera década del siglo XX con la formación de sociedades balleneras en Punta Arenas, Chiloé y Valdivia (Martinic 2004; Nicholls 2010; Quiroz 2010). La llegada de los noruegos a comienzos del siglo XX producirá cambios significativos en el oficio ballenero chileno, pero no hará desaparecer sus características anteriores, derivadas de la tradición norteamericana, sino más bien se superpondrá, generando una suerte de melting pot ballenero.

Después de la Segunda Guerra Mundial surgen dos modelos empresariales diferenciados, aunque no antagónicos, en la industria ballenera chilena. El primero, representado por la INDUS, era un negocio a gran escala, cuya finalidad era asegurar la materia prima para la elaboración de sus productos comerciales como jabones, detergentes, velas, aceites y margarinas. El segundo, representado por la empresa Macaya Hermanos, era un negocio familiar a pequeña escala, cuya finalidad era la producción y venta directa de aceite y abono (Quiroz 2014). La industria ballenera entra en crisis a mediados de los años 60 y las tres plantas cierran sus puertas: Bajo Molle en 1965, Quintay en 1967 y Chome en 1983, cuando se caza la última ballena en aguas chilenas (Pastene y Quiroz 2010). 


\section{La Etnografía Retrospectiva}

El término "etnografía retrospectiva" surge en el contexto de un diálogo, a veces interrumpido, entre antropología e historia. El sociólogo e historiador norteamericano Charles Tilly señala que "a primera vista, antropólogos e historiadores parecen haber sido hechos el uno para el otro", incluso se podría pensar que "su romance estaba destinado a concretarse y que era probable que prosperara, después de todo, ambos tienden a ser fastidiosos respecto de lo particular, incluso cuando esperan generalizar". Pero una mirada más fina puede descubrir "posibles fuentes de disenso entre los inamorati", ya que "los historiadores tienden a estar especialmente interesados en fijar las acciones humanas en el tiempo y menos interesados, o ambivalentes, respecto de fijarlas en el espacio", mientras que los antropólogos "tienden a estar mucho más apegados al lugar y un poco más relajados respecto de fijar las acciones en el tiempo" (Tilly 1978:207-208).

El antropólogo Michel Herzfeld describe la relación entre las disciplinas como la de una larga danza donde "la antropología y la historia han bailado un coqueto pas de deux a lo largo de todo el siglo pasado" (Herzfeld 2001:55).

En este trabajo utilizaremos el concepto "etnografía retrospectiva" en el sentido enunciado por el historiador inglés Keith Thomas cuando indica que el proyecto, "en el que intermitentemente ha estado comprometido gran parte de [su] vida académica", ha sido "construir una etnografía retrospectiva de la Inglaterra moderna temprana, abordando el pasado de la misma manera como un antropólogo aborda una sociedad exótica" (Thomas 2009:2). Thomas publica en 1963 un artículo muy influyente donde enunciaba la relevancia que para los historiadores tienen los estudios antropológicos. Señala que los estudios serios pertinentes a "sociedades remotas solo pueden hacerse después de un intensivo trabajo de campo en el que el antropólogo ha observado por sí mismo las interconexiones entre los hechos sociales"; en cambio, el historiador tiene que basarse, a menudo, "en su imaginación para trazar lazos o deducir consecuencias que los antropólogos pueden ver ante sus ojos". Thomas finaliza con una pregunta: “¿es demasiado suponer que el historiador que está familiarizado con los hallazgos de los antropólogos está en una mejor posición para formular preguntas inteligentes relativas a su material y tiene más probabilidades de encontrar respuestas inteligentes?" (Thomas 1963:17). El texto era un elaborado y empático eco de un trabajo publicado en 1961 por el antropólogo inglés E. E. Evans-Pritchard, que subrayaba la convergencia de la historia (al menos, de algún tipo de historia) con la antropología, donde las dos disciplinas están tratando fundamentalmente de hacer lo mismo: "traducir un conjunto de ideas en términos de otro al suyo propio, de manera que aparezca inteligible, y ambas emplean medios similares para lograr este fin". Si el antropólogo hace trabajo de campo y el historiador revisa archivos "es una diferencia técnica, pero no metodológica" (Evans-Pritchard 1961:14).

Los trabajos de la antropóloga brasileña Renata de Sá Gonçalves son un buen ejemplo del uso de la etnografía retrospectiva. Nos habla de un "viaje" al Rio de Janeiro de finales del siglo XIX y que, con la ayuda de las voces de periodistas y cronistas, a veces desde dentro otras desde fuera, pudo narrar los dramas desarrollados en el carnaval dos ranchos, las antiguas escuelas de samba (Gonçalves 2007). Para recorrer ese camino, señala, "me dejé llevar [...] por diarios, revistas y libros, de manera de construir una 'etnografía retrospectiva' de su proceso de estructuración, consolidación y finalización" (Gonçalves 2008:7), proponiendo "una lectura etnográfica del material histórico relacionado con los 'ranchos carnavalescos', con un foco en los cronistas del diario considerado como el más 'popular', de la época, el Jornal do Brasil" (Gonçalves 2009:76). Estos cronistas son "comentadores e intérpretes privilegiados del carnaval carioca", pues no solo eran "críticos sino también participantes extremadamente activos en el proceso de formación y en la consolidación de esta forma carnavalesca" (Gonçalves 2009:77).

La etnografía retrospectiva es, en resumen, una herramienta que permite estudiar un modo de vida del pasado como si fuera contemporáneo, utilizando "los mejores equivalentes históricos de las observaciones de los etnógrafos", para que ese modo de vida reconstituido sirva "como contexto para una explicación de la acción colectiva" (Tilly 1978:210).

\section{Una Mirada "Para-etnográfica" de la Industria Ballenera Chilena}

Tenemos un conjunto de descripciones realizadas por personas que participaron, observaron y/o escucharon, en su momento y desde su propia 
contingencia, la caza y procesamiento de las ballenas en las costas de Chile. En la caza tradicional de ballenas destacan los relatos de Dublé Urrutia (1905a, 1905b) y Castillo $(1906,1907)$ y en la caza moderna los de Navarro (1907), Broome (1913) y Coloane (1934).

Estos trabajos representan miradas y voces de no-antropólogos que tuvieron la oportunidad de observar los eventos en un presente etnográfico y, a su manera, contarlos. Los llamamos "etnógrafos equivalentes" en el mismo sentido que D. R. Holmes y G. E. Marcus hablan de los "para-etnógrafos", es decir, "sujetos expertos que no son nativos ni colegas, sino contrapartes" del etnógrafo (Holmes y Marcus 2005:248). Resulta sintomático que el concepto de para-etnografía fuera formulado "para enfrentar los desafíos de desarrollar etnografía antropológica en nuevos contextos de trabajo de campo, principalmente, aunque no de manera exclusiva, en lugares dominados por el conocimiento científico y/o un ethos tecnocrático" (Holmes y Marcus 2008:595).

Hemos escogido dos autores para ilustrar esta mirada "para-etnográfica": Luis Castillo, biólogo, y Francisco Coloane, escritor-periodista, con formaciones disciplinarias diversas, quienes pudieron observar y describir las actividades balleneras en un momento específico de la historia. ¿Son sus observaciones equivalentes las que podría haber hecho un etnógrafo en esa misma época? Este artículo intenta responder la pregunta "de manera oblicua" (Leiris 2007).

\section{I: Los textos de Luis Castillo, biólogo}

Luis Castillo, biólogo de la Sección de Aguas y Bosques del Ministerio de Industrias y Obras Públicas, visita en varias oportunidades las costas del sur de Chile y publica algunos breves artículos referidos a "la pesca de ballenas" $(1906,1907,1937)$.

Uno de sus trabajos más conocidos es un texto respecto de la caza tradicional de ballenas en la isla Santa María (1906), escrito luego una visita a la isla en el invierno de 1905. La metodología de trabajo queda definida por sus propias palabras. Debido a que viajó en época de invierno, "no me fue, por esto, posible tomar parte en las faenas de caza". Se limitó a visitar la isla "recorriéndola en todo su contorno, ocupándome en recoger los datos que estimé necesarios para ilustrar este informe", pero además equipó "una chalupa ballenera con todos los útiles empleados en la caza, procurando que los tripulantes se desempeñaran en sus respectivos cometidos" (Castillo1906:495). La imposibilidad de observar directamente el evento lo lleva a realizar una paciente "simulación", un experimento etnográfico no tan extraño en la antropología. El resultado de sus observaciones y conversaciones en la isla es un breve escrito, de seis páginas, que muestra en toda su complejidad "las primitivas labores con que se realiza la faena" y los precarios métodos "del aprovechamiento industrial" de sus restos (Castillo1906:496).

La primera parte del texto contiene una prolija descripción de las características biológicas de las diversas especies de ballenas que surcan las aguas de la isla Santa María.

La segunda parte corresponde a una detallada descripción de la caza costera de ballenas en la isla Santa María. En la isla, cuando el tiempo lo permite, "siempre hai un hombre apostado en una de las cumbres de la isla, de las más inmediatas a la playa". Explora el horizonte "con ayuda de un anteojo, i cuando ve aproximarse un ejemplar, anuncia la presencia del monstruo a sus compañeros de embarcación, procurando hacerlo con el mayor sigilo". De este modo su descubrimiento no es aprovechado "por los demás colegas de labores, que como el, están en acecho de su presa". Los preparativos para la captura se aceleran: se aparejan y se lanzan al agua las chalupas. Cada chalupa va tripulada por seis hombres: en la popa "el dueño de la embarcación, es a la vez piloto, encargado del manejo del timón i la dirección de la maniobra", en la proa el arponero o trancador "con el arpón empuñado, dispuesto a fijarlo en el animal con certero golpe", entre ellos, "cuatro bogadores". Se inicia la persecución. Una vez acorralada la ballena, con la chalupa a su lado, el piloto da la orden de "trancar" y "el 'trancador' se pone de pié en la proa y lanza el arpón contra la ballena”. Se sabe "que la parte más vulnerable de las ballenas es el costado, más o menos por la mitad del cuerpo". Si el arponero tiene éxito, se dice que la ballena ha sido 'fijada'. Al 'fijar' la ballena, uno de los bogadores, que ha dejado de remar, para controlar su calentamiento por fricción "moja la línea, variando en alguna cierta cantidad de agua, que luego se filtra por los numerosos agujeros practicados en el fondo". Herida la ballena huye, arrastrando el cabo línea que va unido al arpón. En ese momento los tripulantes "proceden a recoger 
la línea con prontitud, hasta notar en ella una marca que les revela la proximidad del cetáceo, que busca la superficie para poder respirar i que se encuentra desde este momento a tiro de lanza". Para maniobrar con la lanza se requiere que el timonel, ayudado del resto de la tripulación, coloque el bote "de manera que pueda desde ahí lanzar el animal en el mismo costado donde fue fijado por el arpón. Se da uno i hasta tres lanzazos, o más bien dicho, le da los que alcanza, recojiendo el arma con presteza, inmediatamente que se hace uso de ella". La ballena, entonces, sintiéndose nuevamente herida, ya de muerte, "se sumerje con lentitud, inclinándose comúnmente de un lado a otro, agoniza tiñendo el agua con su sangre, hasta que luego queda completamente inanimada". Los tripulantes de la chalupa, "se acercan [...] para cerrarle la boca, evitando con esto que el animal de llene de agua i haga más costosa la tarea". Finalmente, "los esforzados bogadores sumerjen sus remos i avanzan arrastrando el monstruo lentamente, guiándose a menudo solo por la luz del faro, sin divisar la playa de la isla". Indudablemente esta tarea es de mucho esfuerzo. Si consideramos que las ballenas se 'fijan' a unas 'tres millas de distancia de la costa de la isla Santa María, dicha distancia se aumenta por el espacio que recorre el cetáceo en su huida i todo esto corresponde al trayecto que se tiene que remolcar el animal para vararlo en la playa". Una vez que la ballena llega a la playa se procede a beneficiarla. Para hacerlo "se corta el animal en tres partes i haciendo tres trozos de la cabeza, el cuerpo i la cola" (Figura 2). Los trozos o 'tajadas' de tocino son de una vara de largo. Este tocino "se hierve en fondos grandes de hierro i así se saca el aceite" (Castillo1906:497-498).

En la isla Santa María, la administración de la hacienda "proporciona dos fondos buenos de 150 galones cada uno, i algunos más que se encuentran en mal estado, de menor capacidad; ocho enfriaderas de aceite de tamaño variable i entre las que la mayor puede contener 800 galones i la menor sólo 300". La utilización de las carcasas no era del todo eficiente: "el cadáver queda botado en la playa después de sacarle la grasa, i no toda, aprovechándose de su carne las gaviotas, jotes, tiuques i pájaros carneros".

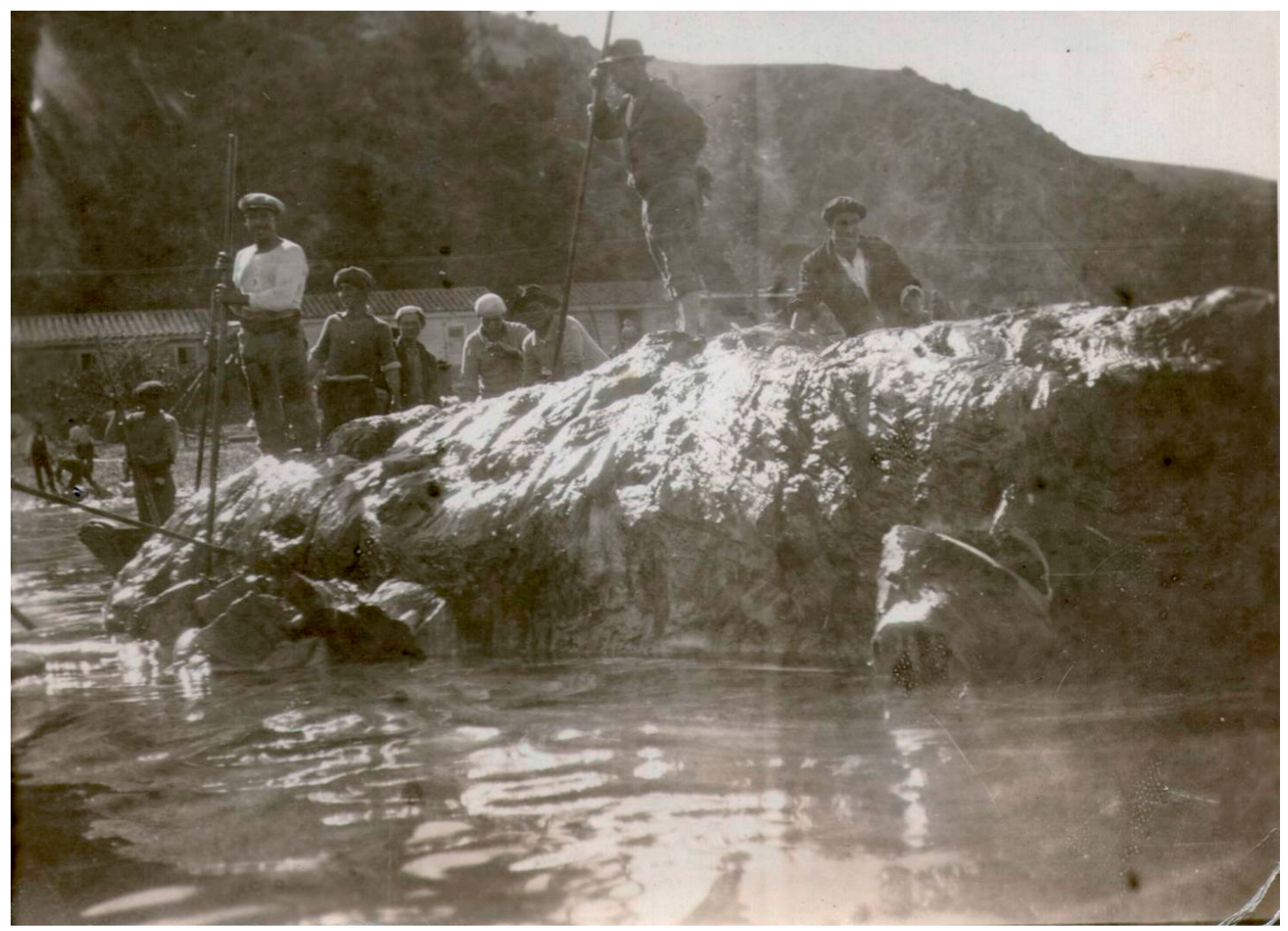

Figura 2. Balleneros en Tumbes a comienzos del siglo XX [Foto gentileza de Luis Salvo, Talcahuano].

Whaling ships in Tumbes in the early twentieth century [Photograph courtesy of Luis Salvo, Talcahuano]. 
Uno de los principales problemas era que, en todo tiempo, "se deja sentir un mal olor aún a distancias considerables, i principalmente en el verano se respira un ambiente de una fetidez pútrida insoportable" (Castillo 1906:498-499).

Castillo entrega en un segundo trabajo, escrito al regreso de un viaje a las costas de Llanquihue y Chiloé realizado en 1906, antecedentes adicionales acerca de "el estado en el que se encuentra la industria de la caza de ballena [...que] abarca en la región de mi referencia a un solo cetáceo de nuestros mares [... la] denominada vulgarmente raituel". En la caza de la ballena franca "se ocupan más de veinte empresas balleneras en las dos provincias de Llanquihue i Chiloé, constituyendo en muchos de esos puntos las tareas preferentes de la población" (Castillo 1907:162). En ese momento, la primera década del siglo XX, "la industria de la caza de ballenas atendida con perfeccionados métodos europeos no ha podido difundirse como sería de desear" (Castillo 1907:158). Castillo señala que las "empresas balleneras de chalupas" tienen grandes ventajas sobre las "de tipo industrial", pues "no consumen combustible, no demandan muchos gastos por las reparaciones de las embarcaciones y no necesitan de una numerosa tripulación con sueldo fijo", aunque los grandes gastos de la caza moderna se compensan "por el espléndido rendimiento comercial". Es preferible una caza costera en pequeña escala, más sustentable", a una caza "de tipo industrial" que requiere el uso de un "vapor ballenero" (Castillo 1907:158-159).

Castillo considera que la raituel o ballena franca es una especie que se encontraría en peligro debido a un "procedimiento inconveniente adoptado en la caza del animal por los balleneros nacionales", que es hacerlo "durante la época de procreación del cetáceo". Con el fin de regular la actividad propone lo que denomina "las bases de un reglamento de caza de ballenas, para que [...] se sirva considerarlas i hacer de ellas materia de una ley" (Castillo 1907:162-163).

Pasarán más de veinte años para que algunas de las recomendaciones de Castillo se incluyan en la Ley de Caza y Pesca promulgada en 1929. Entre las aceptadas no se encuentra aquella que protegía la ballena franca con una veda entre el 1 de junio y el 30 de septiembre de cada año.

Luis Castillo no solo estaba interesado en describir la caza y el procesamiento de las ballenas, sino también en el futuro de la actividad y, en tanto funcionario público, en la participación del Estado en su posible desarrollo y necesario progreso. Para Castillo, "una industria ballenera no requiere de la protección del Supremo Gobierno para progresar", al contrario, "puede vivir i progresar espontáneamente por el esfuerzo particular". La función del Estado solamente es "reglamentar la caza" y preparar "personal competente en escuelas en que puedan, después de un corto estudio, acreditar la competencia requerida" para el desempeño del oficio y "sustraerse de las desastrosas consecuencias a las que hoy se exponen en estas peligrosas i mal remuneradas tareas" (Castillo 1906: 499-500).

\section{II: Un reportaje de Francisco Coloane, escritor}

Francisco Coloane es, sin duda, quien más ha escrito acerca de la caza moderna de ballenas en las costas chilenas. ¿Qué ocurre cuando el "dueño de la mirada", el observador-participante, es un escritor de las características de Francisco Coloane?, quién se preocupa de advertirnos que él es "un simple narrador de acontecimientos" que le "ha tocado presenciar, sufrir o inventar", o que le "han contado", recalcando que nunca ha "sabido bien por dónde empiezan la invención y la verdad" (Teillier 1968). En este trabajo no abordaremos su enorme contribución al tema sino solamente su participación como "testigo" de un evento ballenero ocurrido en las costas chilenas y el uso que hace de la información obtenida en algunas de sus obras literarias.

En 1934 el escritor tuvo la oportunidad de observar en Puerto Barroso, en el golfo de Penas, como reportero del diario El Magallanes de Punta Arenas, las operaciones balleneras de la Compañía Chileno Noruega de Pesca dirigida por el capitán Adolf Andresen (Quiroz y Carreño 2010). También conversó con los balleneros en varias oportunidades, "allí, charlando amigablemente una noche, los noruegos nos narraron aventuras maravillosas y extrañas visiones boreales de ambos polos, las que dejaremos para una próxima información", incluso "les hice una vez una entrevista a unos noruegos, con intérprete" (Vidal 1991:57-58).

Escribe un relato relativo lo observado y conversado (Coloane 1934:21), que más tarde lo usará en algunas de sus creaciones literarias, primero para escribir el capítulo "La caza de ballenas" de su libro El Último Grumete de la Baquedano (1941:89102) y luego para caracterizar a Dámaso Ramírez, protagonista del cuento "Rumbo a Puerto Edén" (2008 [1956]:387-410). 
En la primera parte de su reportaje Coloane informa en términos generales de la expedición noruega, la llegada en 1933 de los tres buques balleneros a Punta Arenas, el inicio de la caza en Puerto Barroso, las primeras sesenta ballenas capturadas que "el buque madre Presidente Alessandri, equipado con maquinarias modernas, las industrializó en forma tan conveniente que el aceite empezó inmediatamente a conquistar el mercado", los conflictos con la Sociedad Ballenera de Corral, quienes vieron "un peligro para sus intereses en estos poderosos competidores que producían un aceite de óptima calidad, merced a la industrialización flotante de las ballenas, que permite descuartizarlas y derretirlas al día siguiente de la caza", y finalmente la legalización de la empresa con "tripulación chilena y más del $60 \%$ de capital chileno", pues "se repatrió la mayor parte de los tripulantes noruegos" y el señor Alfredo Doberti "se interesó en la empresa y entró a satisfacer la ley, con el porcentaje de capital chileno requerido".

La segunda parte del texto corresponde a una fina descripción de la caza de ballenas y del procesamiento de sus carcasas. La primera etapa de la cacería, una vez que "los dos buques cazadores, Noruega y Chile, abandonan el refugio donde queda estacionada la industria flotante del Presidente Alessandri", corresponde al denominado avistamiento. Para ello, "en la cofa, dentro del característico 'barril', ya hay un vigía que recorre con sus ojos la dilatada superficie del mar". Coloane señala que "las olas sacuden a veces la pequeña embarcación en tal forma que permanecer en ese puesto barrido por las aguas es un heroísmo continuado de viejos lobos de mar". La guardia en el 'barril' se hace cada dos horas, y es obligación para todos, desde el capitán hasta el último grumete. Cuando el vigía descubre, por el esputo o chorro de agua, la ballena, el capitán se hace cargo de las maniobras: "toma posesión del timón y, con verdadero instinto, con una astucia de cazador hecha sangre, calcula el lugar en que irá a salir el animal después de una zambullida, y hacia allá lanza el barquichuelo haciendo una verdadera cortada". El piloto, otro avezado cazador, "está junto al cañón, sentado en la misma 'rada' del buque". Cuando la ballena aparece en la superficie del agua, "el barco está encima maniobrando rápidamente en zigzag, a una distancia de 30 a 40 m, y el cañón buscando hábilmente el lugar sensible por donde irá a introducirse el arpón”. Es un momento crucial.
¡Se produce una detonación y a los seis segundos otra! ¡En las entrañas colosales ha explotado la granada! Las espoletas se abren y hacen carne. La ballena herida huye velozmente, "los carreteles van desenrollando cable y más cable, hasta que se producen los estirones que amortigua el resorte, y el gigante del mar muere". El texto finaliza con la siguiente frase: "Todo ha sido sencillamente emocionante. Una vez que el coloso ha muerto, todos parecen lanzar un suspiro de alivio". Una vez que el animal ha muerto, el barco se acerca recogiendo el cable y, sobre el cuerpo de la ballena, los marineros "introducen un asta de hierro de ocho m, a cuyo extremo una bandera flamea con el nombre del buque como insignia grotesca del animal caído. Se abandona la ballena a la deriva, y el barco continúa la caza". Cuando termina la jornada diaria, "los dos cazadores empiezan a recoger sus piezas conquistadas y las remolcan despaciosamente hasta el costado del buque madre" (Figura 3). Cuando entregan las ballenas, comienza su procesamiento "con personal idóneo", que es realizado al costado o en el buque factoría. Coloane indica que "sobre los cuerpos de las ballenas que están a flor de agua, se desarrolla el descuartizamiento y luego los trozos de carne son izados al interior del buque, por medio de las plumas y maromas" (Coloane 1934:21).

La primera vez que Coloane usa los datos obtenidos en Puerto Barroso es en su novela $E l$ último Grumete de la Baquedano, publicada en 1941. Relata que la Baquedano, luego de doblar el cabo de Tres Montes, se encuentra en la bahía de Puerto Refugio, en la parte norte del golfo de Penas, con "una flota ballenera, con el buque madre y cuatro pequeños cazadores", que, como ellos, "capeaba el temporal" (Coloane 1941:87). En el capítulo denominado "La caza de ballenas" Coloane describe un evento de caza en el que participan los marineros de la Baquedano, a bordo del buque Noruega, uno de los cazadores de la flota ballenera (Coloane 1941:95-102), usando la información que le fuera entregada por sus entrevistados en el golfo de Penas.

Es interesante observar las diferencias y semejanzas en sus descripciones del cañón arponero. En el libro Coloane dice que el arpón "es un fierro aguzado de más o menos un metro de largo y dos pulgadas de diámetro [...] en su punta lleva recogidos tres o cuatro fierros más pequeños que se abren [como] los rayos de un paraguas cuando el arpón ha penetrado en el cuerpo de la ballena" 


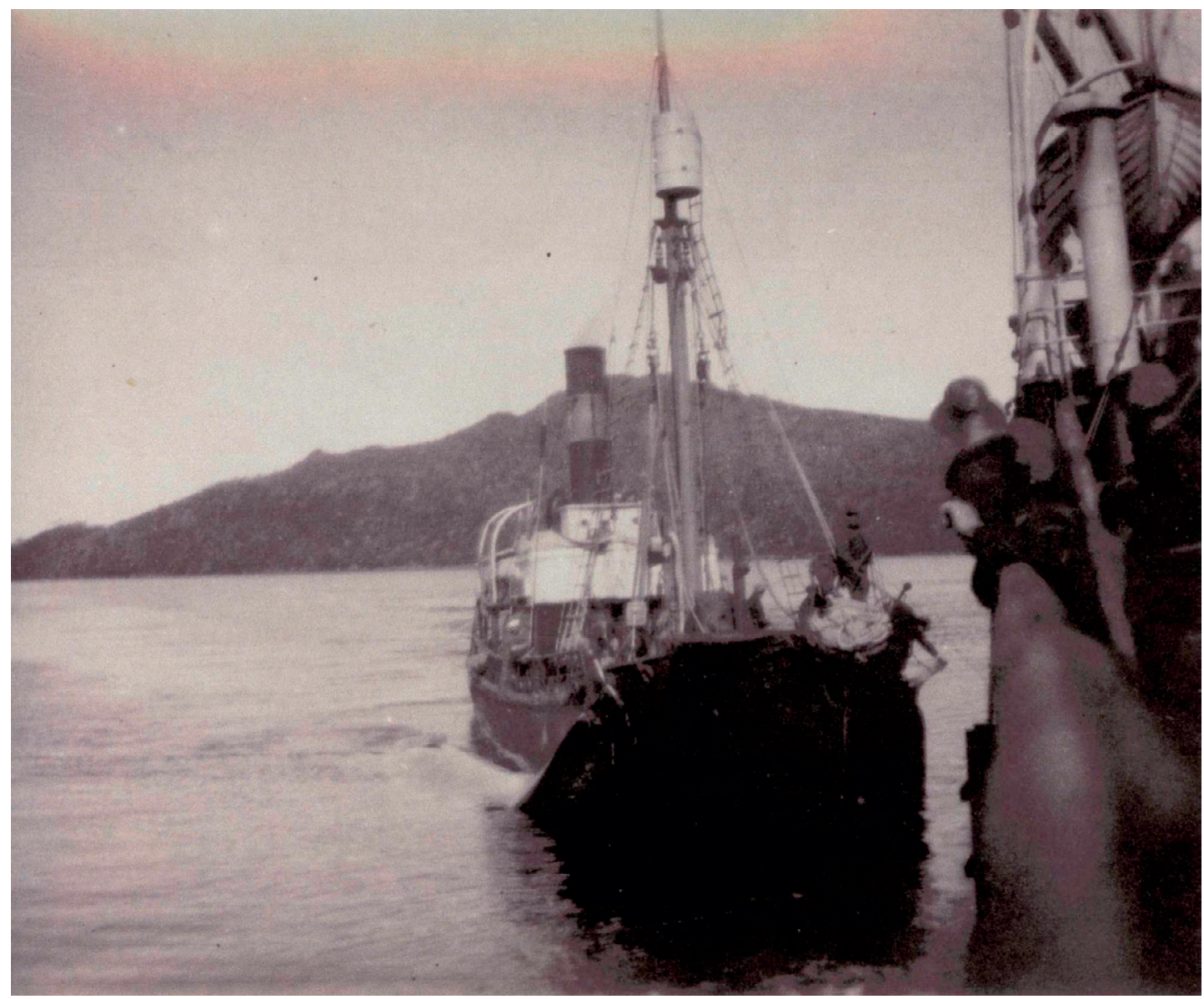

Figura 3. El cazador Noruega haciendo entrega de sus capturas al buque factoría Presidente Alessandri en Puerto Barroso, 1934 [Foto gentileza Harald Fevang, Sandefjord, Noruega].

The Noruega whaling ship delivering its catches to Presidente Alessandri factory ship in Puerto Barroso, 1934 [Photograph courtesy of Harald Fevang, Sandefjord, Norway].

(Coloane 1941:96). En el reportaje señala que el arpón "mide más de un metro cincuenta de largo por tres pulgadas y media de diámetro y pesa alrededor de cien kilos [...] lleva en el extremo cuatro horquillas o espoletas de $85 \mathrm{~cm}$, amarradas fuertemente a una granada de 450 gramos de pólvora" (Coloane 1934:21). El arpón va unido a un cable de manila de casi mil metros que se enrolla "en grandes carreteles en el fondo del barco, y adherido a un resorte gigantesco, que permite que el buque no se dé vueltas o se haga trizas con los formidables estirones de alguna ballena herida" (Coloane 1934:21). La ballena herida se lanza a toda velocidad "y el cable empieza a desenrollarse desde un tambor que hay en el fondo de la bodega y que tiene, además, un gran resorte de acero, para amortiguar los tirones de los últimos estertores" (Coloane 1941:96).
La segunda vez que utiliza la información es en el cuento "Rumbo a Puerto Edén" publicado en 1957 como parte del libro Tierra del Fuego. En ese cuento se caracteriza a su protagonista Dámaso Ramírez como un exballenero que "había descendido a gobernar esa goleta chorera, debido al cierre de la factoría ballenera en que trabajaba”. Esta era "una compañía chileno-noruega que se había atrevido a instalarse en la región del golfo de Penas con un buque-fábrica y cuatro cazadores, uno de los cuales, el Chile, capitaneaba él". Sin embargo, "las esferas gubernativas habían dejado caer un rayo de maldición contra la incipiente industria, pues le estaba haciendo competencia a otra compañía ballenera instalada en el norte", cuyo propietario, en apariencia "un hombre de gran influencia social y económica, era amigo del Presidente de la República”. La compañía había quebrado y 
"tuvo que liquidar y vender su buque-fábrica y los cuatro cazadores a la misma poderosa competidora del norte". De esta manera, "Dámaso Ramírez había perdido su trabajo, su categoría de capitán ballenero y algo más, la fe en los hombres, sobre todo cuando eran gobernantes". Coloane finaliza indicando que "como buen ballenero acostumbrado a vencer la gran bestia del mar, pensaba que, aunque el hombre había llegado a dominar la naturaleza, no había logrado aún dominar su propia naturaleza" (Coloane 2008:401).

En este caso Coloane aprovecha de incorporar información respecto de las dificultades en el funcionamiento de la empresa ballenera, información que había sido difundida por la prensa regional de la época, señalando que la empresa era la Sociedad Ballenera de Corral, empresa valdiviana (Quiroz y Carreño 2010). El escritor sugiere que detrás estaba la INDUS, empresa que adquirirá en 1935 la Sociedad Ballenera de Corral (Figura 4), y con ello se llevará la caza de ballenas "al norte" (Quiroz y de la Fuente 2012). La caza de ballenas se transformaba en una empresa dominada por los grandes capitales y eso significaba un enorme cambio en la relación entre los hombres y los cetáceos.

\section{Final}

Las ballenas y su caza han estado en el imaginario de las personas desde hace varios miles de años y ha experimentado varios cambios en el tiempo, algunos de los que pueden detectarse en las producciones culturales del siglo XX (Lawrence y Philips 2004:698). Los cambios han significado que, en los discursos, la caza de ballenas pasó de ser considerada una actividad heroica, donde el hombre ponía en juego su propia vida en un combate contra un monstruo aterrador, a una actividad deleznable, cruel, innecesaria, en la que el hombre muestra lo peor de sí mismo ante una criatura prácticamente indefensa. El antropólogo noruego A. Kalland (2009) ofrece un interesante análisis de los discursos anti y proballenero, aunque reconoce su parcialidad, pues "mi principal simpatía está con los balleneros" (Kalland 2009:x). Entre todos los animales, las ballenas han sido transformadas en seres únicos: la "superballena", un "constructo conceptual" que reemplaza "un reconocimiento apropiado de las setenta y cinco especies diferentes incluidas en el orden taxonómico de los cetáceos", oscureciendo las actuales circunstancias ecológicas de cada especie

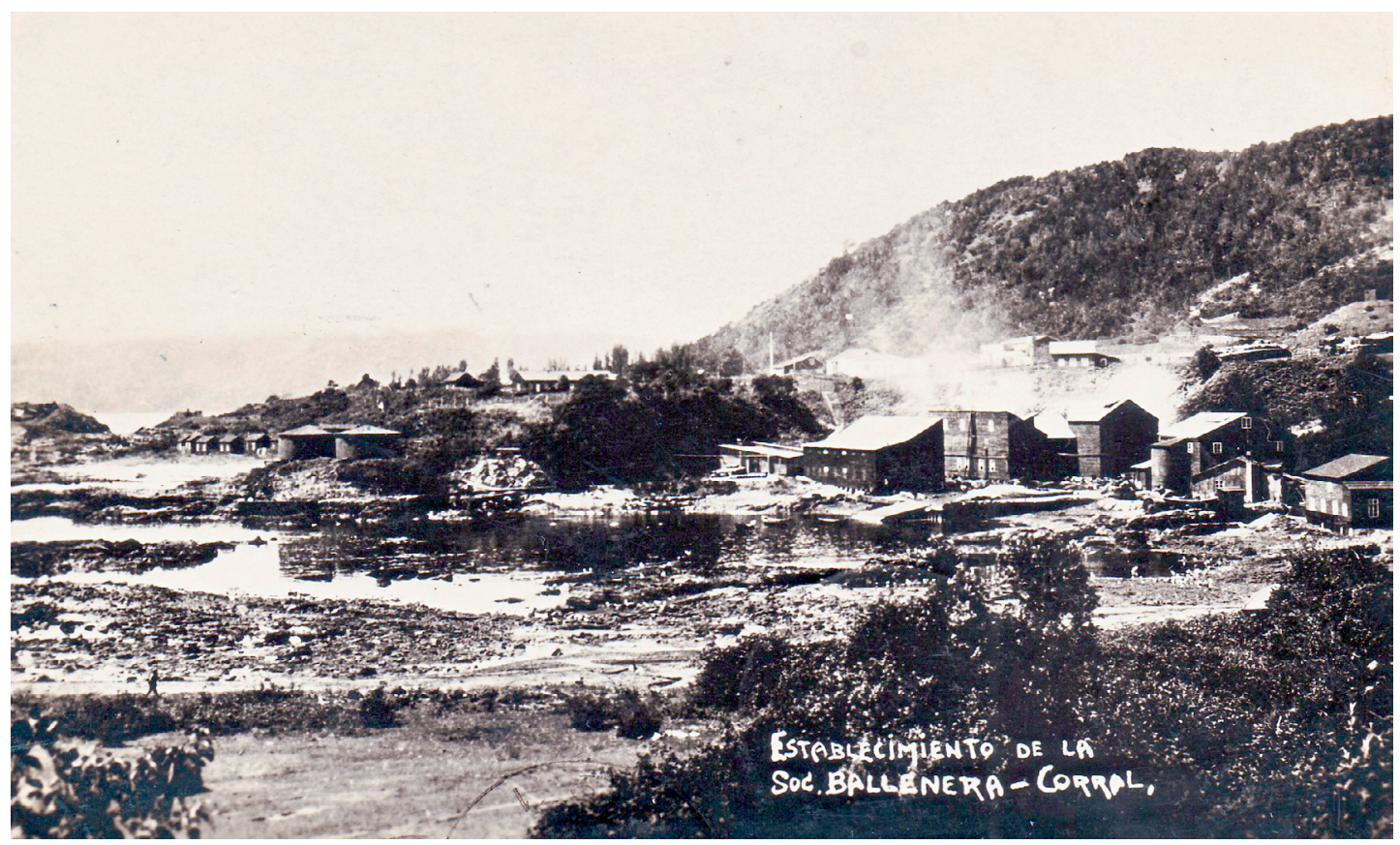

Figura 4. Planta ballenera de San Carlos de Corral, 1930 [Tarjeta postal gentileza Erik Evensen, Tonsberg, Noruega]. Whaling facility in San Carlos de Corral, 1930 [Postcard courtesy of Erik Evensen, Tonsberg, Norway]. 
de ballena: "todas las ballenas están en peligro y todos los balleneros son unos bárbaros" (Kalland 2009:59). En Occidente existe un discurso antiballenero dominante, que ha reemplazado "el ciclo de consumo de las ballenas" de los balleneros por "el ciclo de consumo de la superballena", mediante la masificación del turismo, la personificación de la ballena y la generación de un discurso que la describe como una propiedad común y no como un recurso de acceso abierto (Kalland 2009:135). El discurso antiballenero se ha movido desde un fundamento ecológico a uno ético. Las ballenas han sido "reconstruidas", ya no son recursos que deben ser cosechados ni especies que deben ser salvadas, sino más bien individuos que exhiben conductas casi humanas, que deben ser apreciados y respetados (Lawrence y Philips 2004: 698).

Lo más importante en los relatos de nuestros para-etnógrafos es que no se limitan a describir lo observado y a transcribir lo conversado. Manifiestan opiniones que transmiten a sus lectores. Es una enseñanza que los etnógrafos contemporáneos debemos recoger y no olvidar.

Durante abril de 1953 Coloane visita Quintay para "participar en una cacería de ballenas a bordo de un barco de la flota ballenera de la empresa Indus" (Coloane 2002:290), el Indus 11. Los datos recogidos en esa oportunidad le sirven para escribir un largo reportaje denominado Los balleneros de Quintay, publicado cuando la caza de ballenas en ese lugar era solo un recuerdo (Coloane 1972). Transformado en cuento, el relato finaliza con la siguiente frase: "No he regresado a Quintay porque hoy es un lugar desolado, sin cachalotes ni balleneros. Solo la trompa del cerro Curauma se asoma en la playa oceánica con el grito universal del Green Peace" (Coloane 2002:305).

Castillo señala que "los cetáceos han sido de tal modo perseguidos, que los pocos sobrevivientes de esta persecución inmoderada han debido recluirse en una zona que ya no puede seguir disputándole el hombre, sino muy de tarde en tarde": los mares árticos y antárticos. Recuerda a los antiguos balleneros chilenos, "en esos tiempos [... cuando] el animal era atrapado con una audacia temeraria realmente inconcebible para una época tan cobarde e incolora como la presente". Todo lo hacían "desde una chalupa tripulada por ocho hombres, sin miedo [...]. Eran esos otros tiempos, que no se han ido del todo. Tiempos de menos pericia profesional quizás, pero de más cachaza”. Después vino la caza moderna, característica de esta época "tan cobarde e incolora", donde la industria ballenera "dígase lo que se diga, [...] es ante todo una industria noruega" (Castillo 1937:43-44).

Francisco Coloane plantea el dilema al que se ve enfrentado el ballenero cuando aparecen como blancos la ballena madre y su cría. En el libro $E l$ Último Grumete de la Baquedano, Coloane indica que la madre es cazada y su ballenato no: "Al iniciar el remolque, el Noruega con su ballena al costado, surgió en la superficie nuevamente el pequeño y hermoso ballenato al lado de su madre muerta. ¡Disparémosle!, propuso alguien. ¡No, dijo el capitán; el cazador debe matar solo lo necesario!" (Coloane 1941:101-102). La misma situación enfrenta el protagonista de El camino de la Ballena: “QQué le pasó al piloto?, preguntó Pedro Nauto desde el timón. Ha muerto una ballena madre recién parida, le dijo el capitán, y agregó: ¡Eso no lo debe hacer nunca un ballenero que se precie!" (Coloane 1962:208-209). Coloane sueña a su madre "como una ballena en una especie de astillero, $[\ldots]$ y a veces me siento como un ballenato al lado de ella, quien trata de recogerme cuando tengo pesadillas" (Vidal 1991:20).

Coloane nos recuerda que aunque la caza de ballenas sea una tarea cruel y sangrienta, hay ciertos límites que no se pueden transgredir. Comparte la preocupación de Castillo en la necesidad de proteger la vida de la madre y la cría y ambos apelan a un sentido ético que debe existir en la relación del hombre con las ballenas. En sus discursos no está presente la prohibición sino más bien la regulación.

Quiero compartir, finalmente, la mirada nostálgica de Luis Castillo por esa caza "artesanal" de la ballena: "son tan pocos los que sobreviven de ese primitivo y heroico período industrial que se extingue: que de él va quedando solo el recuerdo" (Castillo 1937:43), ese recuerdo de "cuando había que tener mucha pana, bogar rápidamente hacia atrás en cuanto el arpón daba en el blanco, pues, de otro modo, la ballena herida, hundiéndose de cabeza, sacaba fuera del agua su enorme cuerpo, azotándolo sobre el agua en un sentido y en otro, como para demoler lo que encontrase" (Castillo 1937:44). No como la de ahora, en esta época "tan cobarde e incolora", donde no queda espacio para héroes.

Agradecimientos: La información utilizada para escribir este trabajo fue reunida en el marco de los proyectos de investigación financiados por Fondecyt 
1080115 La cacería de ballenas en las costas de Chile: una mirada desde la antropología y 111082 Antropología e historia de la industria ballenera en Chile (1936-1983). Mis sinceros agradecimientos a Luis Salvo, Harald Fevang y Erik Evensen por las fotografías de este texto. Agradezco también a los revisores anónimos de Chungara Revista de Antropología Chilena, pues sus sugerencias han sido muy valiosas para estructurar de mejor modo la versión final de este artículo.

\section{Referencias Citadas}

Azpiazu, J.A. 2000. Balleneros vascos en el Cantábrico. Ttarttalo, San Sebastián.

Benedetti, M. 1974. Hombre que mira a través de la niebla. En Poemas de Otros, pp. 7-8. Alfa Argentina, Buenos Aires.

Bloch, M. 2008 [1914]. Crítica histórica y crítica del testimonio. En Historia e Historiadores, pp. 18-27. Akal, Madrid.

Broome, H.A. 1913. The Log of a Rolling Stone. The Riverside Press Limited, Edinburgh.

Brown, S.G. 1976. Modern whaling in Britain and the north-east Atlantic Ocean. Mammal Review 6:25-36.

Cartes, A. 2009. Los Cazadores de Mocha Dick. Balleneros Chilenos y Norteamericanos al Sur del Océano de Chile. Pehuén, Santiago.

Castillo, L. 1906. La pesca de la ballena en la isla Santa María. Boletín de la Sociedad de Fomento Fabril 8:495-500.

Castillo, L. 1907. La reglamentación de la caza de ballenas. Anales Agronómicos II:157-165.

Castillo, L. 1937. En torno a la industria ballenera. Acción Social 65:39-46.

Coloane, F. 1934. Flota ballenera. El Magallanes, 16 de septiembre de 1934. Imprenta El Magallanes, Punta Arenas.

Coloane, F. 1941. El Último Grumete de la Baquedano. ZigZag, Santiago.

Coloane, F. 1962. El Camino de la Ballena. Zig-Zag, Santiago. Coloane, F. 1972. Los Balleneros de Quintay. Quimantú, Santiago. Coloane, F. 2002. Tierra del Fuego. Alfaguara, Santiago.

Coloane, F. 2008. Cuentos Completos. Alfaguara, Santiago.

Davis, L.E., R.E. Gallman y K. Gleiter 1997. In Pursuit of Leviathan: Technology, Institutions, Productivity and Profits in American Whaling, 1816-1906. The University of Chicago Press, Chicago.

Dublé Urrutia, D. 1905a. Tumbes (IV). La pesca de la ballena. José Olivares i las ballenas. El Sur, 5 de febrero de 1905. Talleres El Sur, Concepción.

Dublé Urrutia, D. 1905b. Tumbes (V). La caza de la ballena. El Sur, 7 de febrero de 1905. Talleres El Sur, Concepción.

Evans-Pritchard, E.E. 1961. Anthropology and History. Manchester University Press, Manchester.

Fernández, A. 1964. La Caleta y su Gente: Tumbes (Estudio Etnográfico). Memoria de Prueba para optar al Título de Profesor de Estado. Universidad de Concepción, Concepción.
Gonçalvez, R. de Sá 2007. Os Ranchos Pedem Passagem. Secretaria Municipal das Culturas, Rio de Janeiro.

Gonçalvez, R. de Sá 2008. A Dança Nobre no Espetáculo Popular. A Tradição como Aprendizado e Experiencia. Tesis para obtener el título de Doctor en Ciencias Humanas (Antropologia Cultural). Universidade Federal do Rio de Janeiro, Rio de Janeiro.

Gonçalvez, R. de Sá 2009. Sociabilidades Urbanas: cronistas e ranchos carnavalescos no Rio de Janeiro. En As Festas e os Dias: Ritos e Sociabilidades Festivas, editado por R.S. Gonçalves y M.L.V. de C. Cavalcanti, pp. 77-93. Contracapa, Rio de Janeiro.

Hernández, J. 1998. Donde Viven las Ballenas. Actividades Balleneras en la Isla Santa María y Chome del Pionero Juan Macaya Aravena. Aníbal Pinto, Concepción.

Herzfeld, M. 2001. Anthropology: Theoretical Practice in Culture and Society. Blackwell, Oxford.

Holmes, D.R. y G.E. Marcus 2005. Cultures of expertise and the management of globalisation: towards a re-functioning of ethnography. En Global assemblages: technology, politics and ethics as anthropological problems, editado por A. Ong y S. Collier, pp. 235-252. Blackwell, Oxford.

Holmes, D.R. y G.E. Marcus 2008. Para-ethnography. En The SAGE Encyclopedia of Qualitative Research Methods, editado por L.E. Given, pp. 595-597. Sage, Los Angeles.

Kalland, A. 2009. Unveiling the Whale. Discourses on Whales and Whaling. Berghan, New York.

Lawrence, T.B. y N. Philips 2004. From Moby Dick to Free Willy: Macro-cultural discourse and institutional entrepreneurship in emerging institutional fields. Organizations 11:689-711.

Leiris, M. 2007. El África Fantasmal. Pre-textos, Valencia.

Martinic, M. 2004. Antecedentes históricos sobre la caza de cetáceos en Chile. Boletín Antártico Chileno 23:7-12.

Navarro, L. 1907. Censo General de Población, Edificación, Industria, Ganadería i Minería del Territorio de Magallanes, República de Chile. Imprenta de El Magallanes, Punta Arenas.

Nicholls, N. 2010. La Sociedad Ballenera de Magallanes: de cazadores de ballenas a héroes que marcaron la soberanía nacional. Historia 43:41-78.

Pastene, L.A. y D. Quiroz 2010. Outline of the history of whaling in Chile. En Human Culture from the Perspective of Traditional Maritime Communities, editado por International Center for Folk Culture Studies, pp. 73-98. Kanagawa Shimbun Press, Kanagawa.

Pereira Salas, E. 1971. Los Primeros Contactos entre Chile y los Estados Unidos, 1778-1809. Andrés Bello, Santiago. 
Quiroz, D. 2010. Una breve crónica de la cacería de ballenas en Valdivia (1906-1936). Revista Austral de Ciencias Sociales 19:75-98.

Quiroz, D. 2012. Cazadores Tradicionales de Ballenas en las Costas de Chile (1850-1950). Centro de Documentación de Bienes Patrimoniales, Dirección de Bibliotecas, Archivos y Museos, Santiago.

Quiroz, D. 2014. Cazadores Modernos de Ballenas en las Costas de Chile (1905-1983). Centro de Documentación de Bienes Patrimoniales, Dirección de Bibliotecas, Archivos y Museos, Santiago.

Quiroz, D. y G. Carreño 2010. El último sueño del capitán "Adolfus" Andresen: la caza de ballenas en aguas magallánicas (1933-1935). Magallania 38:37-60.
Quiroz, D. y P. de la Fuente 2012. Las operaciones balleneras de la INDUS en aguas patagónicas: los años iniciales (1936-1939). Magallania 40:7-20.

Teillier, J. 1968. Entrevista con Francisco Coloane. Árbol de Letras 6:54-55.

Thomas, K. 1963 History and Anthropology. Past and Present 24:3-24.

Thomas, K. 2009. The Ends of Life: Roads to Fulfillment in Early Modern England. Oxford University Press, Oxford.

Tilly, Ch. 1978. Anthropology, history and the Annales. Review I:207-213.

Tønnessen, J.N. y A.O. Johnsen 1982. The History of Modern Whaling. University of California Press, Berkeley and Los Angeles.

Vidal, V. 1991. Testimonios de Francisco Coloane. Universitaria, Santiago. 